\title{
Ainda é preciso ser neopirrônico ${ }^{1}$
}

\author{
Waldomiro J. Silva Filho \\ Universidade Federal da Bahia (UFBA)
}

\section{RESUMO}

Este artigo trata de duas questôes: por que o modo como o neopirrônico conduz a sua atividade filosófica seria mais virtuoso do que o faz o seu colega não-pirrônico, dogmático? E por que o resultado que ele alcança seria mais valioso? Posto isso, minha resposta à primeira pergunta é que o modo como o neopirrônico investiga é mais virtuoso porque procura evitar deliberadamente os vícios da precipitação, arrogância e fechamento mental. Em relaçáo à segunda pergunta, sugiro que o resultado da investigação do neopirrônico, qualquer que seja (mesmo que não seja a verdade) é mais valioso por causa do modo como ele conduz sua investigação.

\begin{abstract}
This article deals with two questions: why would the way in which the neopyrronicle conducts his philosophical activity be more virtuous than his dogmatic, non-pyrrhic colleague does? And why would the result he achieves be more valuable? That said, my answer to the first question is that the way the neo-Pyrrhonian investigates is more virtuous because it seeks to deliberately avoid the vices of precipitation, arrogance and mental closure. Regarding the second question, I suggest that the outcome of the neopyronic investigation, whatever it may be (even if it is not the truth) is more valuable because of the way he conducts his investigation.
\end{abstract}

\footnotetext{
1 Agradeço os comentários, críticas e sugestôes de Plínio J. Smith. Este artigo foi escrito sob os benefícios de Bolsa de Produtividade em Pesquisa do CNPq (Proc. n. 3I2III/20I6-9).
} 
Assim como a paixão pela religiáo, a paixão pela filosofia, embora tenha por alvo a correção de nossa conduta e a extirpação de nossos vícios, parece sujeita ao inconvenienente de que, pelo seu manejo imprudente, pode servir apenas para fortalecer uma inclinação que já predomina e já atrai em demasia, em função das tendências e inclinaçóes de nosso temperament natural. É certo que, ao buscarmos atingir a elevação e firmeza spiritual do sábio filósofo e esforçarmo-nos para confirmer nossos prazeres exclusivamente ao campo de nossas próprias mentes, poderemos acabar tornando nossa filosofia semelhante à de Epicteto e outros estoicos, ou seja, simplesmente um sistema mais refinado de egoism; e persuadir-nos pelo raciocínio a nos afastar de toda a virtude assim como dos prazeres do convivio social. (grifos meus)

David Hume, Investigaçôes sobre o Entendimento Humano, V, I

O conflito entre dogmatismo e o ceticismo nos apareceu [...] como a vida mesma da filosofia. O dogmatismo sempre renasce, tal como seu incansável adversário, sob mil e distintas formas e roupagens. Nada nos faz esperar que esse confronto venha a ter um fim. A razão crítica não poderá jamais ensarilhar suas armas. Eis porque se terá de repetir a cada momento que ainda é preciso ser cético.

Oswaldo Porchat, "Ainda é preciso ser cético"

\section{Ainda é preciso ser neopirrônico?}

I. Diz-se que ainda é preciso ser neopirrônico por duas razôes: porque o neopirronismo promove uma atitude crítica em relação às especulaçóes filosóficas e porque ele nos lembra de que devemos observar a vida comum, trazendo a filosofia para o espaço humano.

Mas dizer isso obviamente não é bastante, sobretudo porque muitas outras filosofias prometem algo semelhante. Ter uma atitude crítica e se orientar na observação da experiência mundana não é privativo do ceticismo pirrônico. É regra que as filosofias estejam comprometidas com os rigores da investigação disciplinada e cultivada e com uma severa crítica das doutrinas; no mais das vezes, os filósofos estão empenhados na crítica das próprias opiniões, levando seriamente em consideração as objeções às suas ideias e travando animados debates com opositores. Do mesmo modo, parece que todas as filosofias estão, de um modo ou de outro, ocupadas com temas relevantes e indispensáveis à condição humana. A ausência desses elementos (o rigor, a crítica, a autocrítica, a observância dos problemas humanamente relevantes) caracteriza as más filosofias, aquelas que raramente nos atraem a atenção. 
2. Poder-se-ia acrescentar que ainda é preciso ser neopirrônico porque o ceticismo, diferente das outras filosofias e da nossa inclinação natural, conduz à suspensão de juízo. Realmente, se quisermos caracterizar o ceticismo pirrônico seria preciso salientar ao menos quatro pontos. Em primeiro lugar, estamos todos de acordo que o traço peculiar que o filósofo pirrônico atribui à sua própria atividade é o combate às filosofias que se apresentam como portadoras da Verdade e capazes de revelar o Real. Em segundo lugar, o pirrônico também insiste que o combate ao dogmatismo tem como efeito abandonarmos os dogmas e pensamentos especulativos e nos voltarmos tão-somente para a experiência não-filosófica da vida cotidiana no mundo físico e humano em que estamos mergulhados com outras pessoas. Em terceiro lugar, para fazer essas duas coisas - a crítica do dogmatismo e a celebração da vida comum —, o pirrônico se empenha deliberadamente na realização de uma investigação que, usando sofisticadas técnicas e ferramentas metodológicas elaboradas por inúmeros filósofos, possibilita: a) exibir o infindável conflito das opiniōes filosóficas, b) demonstrar a equivalência epistêmica dessas opinióes e c) conduzir à suspensáo do juízo acerca do tema da investigação. Por fim, mesmo não alcançando a verdade, o pirrônico encontra - como consequência da pura sorte —um bem ainda mais valioso do que a verdade, qual seja, a tranquilidade da mente acerca das perturbaçóes que o mobilizaram a iniciar a sua investigação.

Curiosamente, os filósofos pirrônicos e seus colegas não-pirrônicos têm à sua disposição os mesmos recursos e ferramentas intelectuais e ambos, no ponto de partida, puseram-se a filosofar na intençáo de conhecer, com o propósito de explicar e interpretar o mundo, encontrar a verdade, a certeza, os princípios etc. A despeito disso, enquanto alguns afirmam categoricamente que suas elaboradas teorias especulativas exibidas nos seus discursos filosóficos anunciam a Verdade ou o Primeiro Princípio e outros, do mesmo modo e com a mesma ênfase, que suas filosofias provam que não se pode chegar a tal coisa, à Verdade ou ao Primeiro Princípio, o filósofo pirrônico declara que foi "conduzido à suspensão de juízo sobre os discursos da filosofia especulativa” e se descobrira no espaço do fenômeno e da vida comum (Porchat, 200I, p. IO-I4) exclusivamente por causa do modo como realizou a investigação.

3. Isso significa que há uma maneira peculiar como o pirrônico conduz a sua investigação e há uma certa satisfação com os resultados dessa investigaçâo que está ausente nos outros filósofos. Por isso, é justo procurar uma resposta para estas duas perguntas: por que o modo como o pirrônico conduz a sua atividade filosófica seria mais virtuoso do que o faz o seu colega náo-pirrônico? E por que o resultado que ele alcança seria mais valioso? 


\section{Algumas capacidades reivindicadas por um cético pirrônico}

4. Mesmo reconhecendo que há uma certa polêmica em torno desse assunto, parece que em algum ponto no início da investigação, os filósofos - tanto aqueles que se tornarão céticos quanto aqueles que se tornarão dogmáticos — compartilham um mesmo propósito e recursos intelectuais semelhantes. Uma investigação intelectual legítima que envolva teses em conflito, no ponto de partida, tem como fim alcançar a verdade e a trajetória dessa investigaçáo, se conduzida de modo racional, rigoroso e virtuoso, deve levar ou à afirmação ou à negação ou à suspensão. Quando aquele que investiga encontra melhores razóes a favor, afirma; quando encontra melhores razões contra, nega. E quando é tempo para suspender o juízo? Ora, quando aquele que investiga encontra, diante das (supostas) mesmas evidências, argumentos de igual valor epistêmico e não lhe parece que qualquer outra evidência esteja disponível ou qualquer novo argumento seja concebível, aí ele se vê obrigado, pelo apego à força da razão, a suspender o juízo.

Não deve ser estranho pensar que no caso de uma investigação filosófica legítima que envolva teses em conflito, conduzida de modo racional, rigoroso e virtuoso, não há como saber de antemão se sim, se não, se nem sim e nem não. No início, não há nem mesmo como saber se a questão — aquilo que origina a investigação — é uma simples disputa verbal ${ }^{2}$ no sentido de uma questão para a qual nunca haverá uma resposta ou, ao contrário, se é uma questão que, no final, tem uma resposta adequada (que se desconhece no início) oferecida pela razáo, pela tradição, pela Natureza ou pela ciência.... Se soubéssemos no início que a questão é uma falsa questão ou que a resposta se encontra em alguma fonte reconhecidamente confiável, não haveria necessidade racional para uma investigação filosófica. Se alguém persiste em uma investigação que já sabe antecipadamente que não lhe levará a uma resposta adequada possível ou que já há uma resposta adequada disponível, isso caracteriza uma atitude intelectual teimosa de uma pessoa ignorante, cínica e negligente, e,

\footnotetext{
2 Há um excelente artigo de Chalmers, 20II, sobre "disputas verbais” em filosofia. Para ele (p. 5I7), as disputas verbais têm um duplo interesse filosófico. Em primeiro lugar, "[m]any philosophical disagreements are at least partly verbal, and almost every philosophical dispute has been diagnosed as verbal at some point. Here we can see the diagnosis of verbal disputes as a tool for philosophical progress. If we can move beyond verbal disagreement to either substantive agreement or to clarified substantive disagreement, then we have made progress. My own view is that the diagnosis of verbal disputes has the potential to serve as a sort of universal acid in philosophical discussion, either dissolving disagreements or boiling them down to the fundamental disagreements on which they turn. To do this, though, we need some general tools to help us determine when a dispute is verbal and when it is not.

"Second, verbal disputes are interesting as a subject matter for first-order philosophy. Reflection on the existence and nature of verbal disputes can reveal something about the nature of concepts, language, and meaning. Later in the article, I will argue that this approach can help to shed light on a number of key issues in these areas."
} 
consequentemente, quebra a cláusula de racionalidade, rigor e virtuosidade que se espera da performance de um filósofo (qualquer filósofo, inclusive os dogmáticos!).

5. Como sabemos, ao contrário da maioria das outras filosofias, mesmo aquelas que professam uma filosofia prática, o ceticismo pirrônico se define negativamente como uma filosofia que não adere a qualquer teoria filosófica anterior, não formula novas doutrinas e discursos filosóficos e não tem um arranjo conceitual estruturado e sistemático. A rigor, o ceticismo pirrônico expressa apenas um tipo de habilidade intelectual que exige grande vigor e perseverança: aquele que aprende as artes céticas deve poder colocar percepçóes e pensamentos opostos frente a frente e, ao se estabelecer que têm força epistêmica igual, suspender o juízo (HP I, 8). Sexto diz que "as percepçóes e os pensamentos opostos” não são sempre aqueles que, de um lado, afirmam e, do outro, negam, mas simplesmente no sentido de pensamentos em estão conflito. Mas é prudente estar alerta para o fato de que Sexto está fazendo um relato sobre o que aconteceu consigo e com aqueles que se filiaram à tradição pirrônica e que lhes levou à suspensão e à tranquilidade. Ele não tem como garantir que toda investigação intelectual levará à suspensão e à tranquilidade (sobretudo esta última, resultado da sorte). A única coisa que ele possui é uma habilidade e a única coisa que pode oferecer é um conjunto de técnicas. Porchat (200I, p. II-I2) escreveu que desde a antiguidade, os pirrônicos vêm utilizando os mais diversos ensinamentos da Sofística, as objeções dos Pré-socráticos com relação aos dados dos sentidos, o método Socrático de pôr à prova as verdades aceitas, a dialética, a argumentação contraditória da Nova Academia, a doutrina estoica da suspensão de juízo etc. E, ao longo da história, essa atividade do cético continua se beneficiando dos avanços das pesquisas nas ciências naturais e formais, do método naturalista, da crítica histórica, da crítica da linguagem e assim por diante.

Com tudo isso, o pirrônico deve ter a capacidade intelectual de estabelecer que os pensamentos opostos têm "força igual” em relação à credibilidade epistêmica ou à falta dela, demonstra-se que nenhum dos pensamentos em conflito possui superioridade epistêmica em relação aos outros pensamentos.

6. Essas capacidades ou habilidades reivindicadas pelo pirrônico entram em ação em duas situaçóes que tipicamente o motivam a filosofar. Em linhas gerais, a motivação do pirrônico para filosofar se encontra nessas duas situaçóes precisas: a) quando é afetado pelas irregularidades do mundo, tem dificuldade sobre ao que dar o seu assentimento e se sente instigado, por honestidade intelectual, a encontrar uma resposta; e b) quando, por amizade, compadece-se do sofrimento mental de um outro filósofo, perdido na trama das suas especulaçóes dogmáticas. A maneira como o 
pirrônico utiliza as ferramentas intelectuais que aprendeu no período da sua formação é diferente nessas duas situaçôes (cf. Bailey, 2002; Machuca, 2018).

No primeiro caso, quando está perturbado pela irregularidade das coisas e imerso na bruma de conflitos de filosofias, ele utilizará seus recursos para investigar na busca do que é verdadeiro e do que é falso na esperança de atingir a satisfação intelectual; por ser talentoso e honesto intelectualmente, ele não ficará satisfeito com qualquer resposta ingênua, apressada, fantasiosa: somente o que é o caso lhe satisfará. Nesse ponto, podemos dizer que ele usa seus recursos em busca de um bem epistêmico: a verdade. No segundo caso, em virtude da sua empatia e generosidade, seu objetivo é ajudar o seu amigo filósofo a se livrar do que lhe causa sofrimento - justamente seu dogmatismo. Aqui sua atividade não tem um fim epistêmico, mas pragmático: curar a doença do dogmatismo e eliminar a perturbação. Neste caso, a pessoa de formação pirrônica não está realizando uma investigação no sentido estrito do termo: ela aplica seus recursos para curar seu amigo porque anteriormente já experimentara sensaçóes semelhantes e supóe poder o conduzir à suspensáo e talvez à tranquilidade (pois assim ocorrera com ela).

7. Os métodos, técnicas e ferramentas de que se utiliza o pirrônico estão disponíveis a qualquer um que os queira usar. Por que alguém escolhe os usar deste modo e fica satisfeito com os resultados, mesmo que não seja a verdade?

Um pouco acima eu escrevi que o ceticismo pirrônico expressa apenas um tipo de habilidade intelectual que exige grande vigor e perseverança... Esse "apenas" serve para acentuar que, para mim, a marca distintiva do pirronismo não está relacionada com alguma teoria ou técnica, mas com certos traços de caráter ou disposiçóes que requerem do filósofo um tipo especial de vigor, empenho, dedicação, perseverança e generosidade. De modo que o propósito do pirronismo é preparar a pessoa para um tipo específico de conduta tanto quando ela se lança em uma investigação quanto quando ela procura tratar o seu amigo adoecido de dogmatismo. Porchat (200I, p. I8-I9), tratando de uma passagem de Sexto (HP I, I7), diz que o discurso cético promove duas capacidades: a capacita para alcançar a epokhé (a capacidade de se libertar da alienação dogmática) e a capacidade para "viver corretamente". Mas por que viver corretamente? Em que sentido corretamente? Corretamente porque o pirronismo seria um "instrumento prático a serviço de uma vida melhor" e porque, liberta da "alienação dogmática", a pessoa se reconcilia com os outros homens e mulheres: "Deixado o dogma de lado, somente tenho o mundo da vida, o mundo dos homens, sou apenas um destes" (Porchat, 200I, p. I7). Este não é um detalhe. 


\section{Uma Visão Cética do Mundo}

8. No seu Uma Visão Cética do Mundo, Plínio J. Smith (20I7) oferece uma apresentação e interpretação crítica do pensamento de Oswaldo Porchat. Além da rica e detalhada leitura interna da obra de Porchat, indicando a trama conceitual e metodológica, fontes, desenvolvimentos e fases, Smith propóe uma instigante interpretação sobre aspectos que nem sempre estiveram claros para os leitores de Porchat. Um desses aspectos diz respeito à tese de que Porchat tenha proposto uma filosofia, o seu neopirronismo, caracterizada como uma visáo cética do mundo. Como se pode constar em artigos centrais de Porchat, como "Sobre o que aparece" (I99I), "Verdade, realismo, ceticismo" (I995), "O ceticismo pirrônico e os problemas filosóficos" (I996) e "Ainda é preciso ser cético" (200I), "A autocrítica da razão no mundo antigo" $(2005)^{3}$, entre outros, o seu ceticismo tem explicitamente duas faces: uma face negativa ou destrutiva (crítica ao dogmatismo) e uma face positiva ou construtiva (uma filosofia centrada na experiência do fenômeno). Para surpresa de alguns, como salienta Smith (20I7, p. I08), a face positiva "é a mais privilegiada e a mais desenvolvida do neopirronismo" de Porchat.

$\mathrm{Na}$ sua fase positiva ou construtiva, o neopirronimo teria duas partes. A primeira explora a dimensão prática do ceticismo e diz respeito às noçóes de fenômeno e modo de vida do pirrônico (Porchat, I99I, p. I2I-I36) e a segunda, propóe uma filosofia cética ou uma visão cética (Ibid., p. I36-I45). Em Porchat (Smith, 20I7, p. III) a própria noção de "investigaçáo" (zétesis) cética, tem um sentido peculiar e não se limita ao puro e simples combate ao dogmatismo; a investigação cética envolveria um projeto filosófico como uma visão cética do mundo que o permitiria "respostas positivas, e não meramente suspender o juízo”. Para Smith (20I7, p. IIO), essa visão cética do mundo representa uma inovaçáo de Porchar em relaçao ao ceticismo antigo. Considerando o modo de vida e as técnicas desenvolvidas pelo cético, a visão cética do mundo envolveria uma série de crenças em três dimensôes: (a) a incorporação da visão comum do mundo; (b) a aceitação não dogmática de teorias científicas (porque essas teorias estão disseminadas na visão comum que o cético compartilha com outras pessoas e porque vê razóes para não aceitar os resultados e explicaçôes das ciências); e (c) o neopirrônico pode formar opinióes a respeito de muitas questôes filosóficas (desde que atinentes ao domínio do fenômeno).

Esta ênfase de Smith à filosofia da visão cética do mundo abre uma nova perspectiva para tratarmos do neopirronismo e da contribuiçáo de Porchat em particu-

3 Todos esses textos estão reunidos em Porchat, 2006. 
lar. Eu quero insistir aqui que a filosofia da visão cética do mundo requer uma reflexão sobre as capacidades, poderes e virtudes intelectuais do filósofo. Voltarei a esse ponto mais adiante.

\section{Os traços de carácter de um pirrônico}

9. Não nos esqueçamos que, do ponto de vista dos traços de caráter, os filósofos tanto aqueles que se tornarão céticos quanto aqueles que se tornarão dogmáticos são pessoas na mesma medida talentosas e honestas intelectualmente. Elas foram igualmente educadas nos costumes e ciência da sua época, dominam um rico e sofisticado repertório das técnicas do pensamento e da argumentação. Entretanto, aos olhos de uma pirrônica, os outros filósofos e filósofas, por mais competentes que sejam, cultivam uma atitude intelectual marcada pela precipitação, vaidade, fechamento mental e arrogância e, com isso, acabam encarcerados a um discurso que, a pretexto de superar o senso comum e ser veículo da transcendência que expressa a intuição do Absoluto, produz uma imagem fantasiosa e delirante. O pirrônico acusa que seus colegas, tanto em relação aos meios (ao modo como conduz seu inquérito) quanto às realizaçôes (suas teorias), seriam vítimas de vícios e fraquezas intelectuais.

Sobre vícios e fraquezas intelectuais, há um interessante debate recente sobre "vice epistemology". Quassim Cassam (2016, p. I60) estabelece que "vícios intelectuais" são traços de caráter que prejudicam uma investigação efetiva e responsável. Heather Battaly (20I4, p. 5I) considera dois cenários, aquele no qual o que importa são os efeitos e consequências e aquele no qual o que importa são os motivos: no primeiro caso, "vícios epistêmicos" são qualidades estáveis que seguramente produzirão maus efeitos ou produtos; no segundo caso, os vícios estão relacionados a má motivaçóes ou falsas concepçóes de um bem epistêmico. Linda Zagzebski (1996, p. I52) lista os seguintes vícios intelectuais: soberba intelectual, negligência, preguiça, covardia, fechamento mental, acreditar pela vontade, insensibilidade aos detalhes, obtusidade e falta de meticulosidade. Cassam (2016, p. I64) acrescenta entre os vícios intelectuais, a credulidade ingênua, quando se adere acriticamente a uma crença sem verificar sua credibilidade.

A epistemologia dos vícios (Cassam, 2019) está preocupada com as performances epistêmicas em geral. Meu problema aqui obviamente não é estritamente epistêmico nem se refere às performances cognitivas em geral; estou me referindo ao fato de que o pirrônico diz que os outros filósofos se tornam dogmáticos porque têm alguns vícios intelectuais. Os vícios intelectuais de que trata a epistemologia dos vícios que podem prejudicar uma investigação num sentido mais amplo, na vida cotidiana, mas não se aplicam aos filósofos (mesmo os dogmáticos), como a preguiça, obtusidade, negligên- 
cia e credulidade ingênua. Platão seria um dogmático (HP I, 223), assim como Carnéades e Clitômaco (HP I, 230), mas ninguém poderia os acusar de serem intelectualmente negligentes, preguiçosos, covardes, obtusos e assim por diante.

IO. O pirrônico se refere à "semi-modéstia" de Xenófanes (HP I, 224), à precipitação de Heráclito (HP I, 2I2) ou ao fato de que frequentemente muitos filósofos assentem "a uma coisa devido a uma vontade clara de fazê-lo e com um tipo de simpatia, como quando o homem desregrado acredita naquele que aprova um modo de vida extravagante" (HP I, 230). Além disso, está patente que o dogmático sofre de uma falta de vontade ou incapacidade de se envolver seriamente com posiçóes intelectuais rivais relevantes ${ }^{4}$. Assim como não expressa grande simpatia por outros homens e mulheres que sustentam opiniōes opostas.

É claro que uma pessoa arrogante, a precipitada, mentalmente fechada pode produzir crenças verdadeiras (até mesmo uma pessoa ignorante, obtusa, em um golpe de sorte, pode chegar a uma crença verdadeira). Não é porque chega ou não chega à verdade que importa. O problema, aos olhos do pirrônico, é que as atitudes dessa pessoa não são atitudes intelectuais virtuosas, sobretudo porque podem ignorar versôes alternativas mais competentes das coisas, abandonar boas evidências e bons argumentos opostos e deixar de reconhecer a inescapável fragilidade epistêmica humana (como demonstram os Modos de Enesidemo (HP I, 35-163) e de Agripa (HP I, I64-I77).

Quando a filósofa pirrônica descreve sua própria prática filosófica, ela declara que ela mesma, mas náo os seus colegas, permanece estritamente apegada aos rigores da razão e ao sentido da humanidade. O pirrônico se vê como uma pessoa especialmente talentosa e especialmente honesta e, por isso, especialmente habilidosa, perseverante, modesto e com a mente aberta; além disso, vê-se como portadora de valores humanos elevadíssimos, pois é filantropa e empática. O combate não apenas ao dogmatismo, mas aos vícios de que são acometidos os filósofos e que os leva ao dogmatismo, é o traço de caráter do pirrônico. Seu empenho, dedicação e perseverança buscam evitar a "semi-modéstia", a vaidade, a precipitação e a crença pela vontade para, com isso, como citamos acima, deixar o dogma de lado, ingressar no mundo da vida, no mundo dos homens e mulheres, onde somos apenas mais um entre eles (cf. Porchat, 200I, p. I7).

II. O fato é que o resultado de tanta virtude, perseverança, responsabilidade, acuidade pode não ser a verdade. Como escreve Porchat (200I, p. IO):

${ }^{4}$ Heather Battaly, 20I8, estabelece uma relação entre fechamento mental e dogmatismo. 
Mas seu amor ao rigor e ao espírito crítico, rigor e espírito crítico que as filosofias desde sempre proclamaram cultivar, conduz ao fracasso seu empreendimento filosófico original. Não encontra o que buscava. (Porchat, 200I, p. Io)

Ele procurava a verdade, mas não a encontrou. Por que ter fracassado nesse projeto não é um fracasso? Por que a suspensão e a tranquilidade satisfazem o pirrônico? Como disse acima, a suspensão de juízo não é uma consequência necessária da investigação filosófica. Apenas sobre aqueles assuntos que se mostram, depois do inquérito, que não estão garantidos por evidências e que não passam pelo crivo dos "modos" é que se suspende o juízo. Mas não há - fora dos livros, artigos, seminários e argumentos filosóficos dogmáticos — como se decidir antecipadamente sobre que assuntos se deve suspender o juízo. A única coisa que temos por garantido é que as pessoas que adotam uma posição racional e não precipitada são pessoas que têm a habilidade de confrontar opiniōes diferentes, buscar melhores razôes e assim por diante. Mas ocorre que aquilo que o inquérito mostra é que, não havendo mais razóes para acreditar do que não acreditar, suspende o juízo. E, por sorte (pura sorte) alcança a tranquilidade. Porém, sobre a tranquilidade o pirrônico não tem qualquer poder, escapa-lhe a capacidade de escolher estar tranquilo, pois mesmo sendo mais valiosa do que a verdade, é fruto da sorte e do acaso.

Por que é a suspensão e não a verdade o resultado satisfatório da investigação pirrônica? Por que não alcançar a verdade não é um resultado frustrante, um fracasso? De fato, frequentemente Porchat (200I, p. 23) diz que o pirronismo é uma "postura", uma "postura crítica" e "suspensiva" que se "complementa por uma prática filosófica" inteiramente orientada para as coisas da vida. E que a tarefa cética de desdogmatização do discurso nunca se pode dar por definitivamente concluída. Eu quero insistir um pouco mais nesse ponto, pois a filosofia da visão cética do mundo não implica apenas que o pirrônico possa aderir a crenças comuns ou científicas, mas que ele adere a crenças por causa do modo como ele orienta sua investigaçáo, usa seus métodos e técnicas, tem uma conduta intelectual sem os vícios dos dogmáticos. O que importa não é somente refutar o dogmatismo, mas educar-se para "não se reconhecer como oráculo do divino" e abandonar "a pretensão de possuir a perspectiva de Deus sobre o mundo" — como aparece aqui-e-acolá nos textos de Porchat. Todo esse trabalho lhe permite "relativizar as proposiçôes" enquanto expressóes pontos de vista próprios e circunscritos a condiçóes, situaçóes, estados particulares, hábitos, costumes, tradiçôes. Por isso, além de se habilitar para o confronto com o dogmático, o pirrônico é aquele que possui e usa um conjunto de ferramentas intelectuais com o propósito de se reconciliar com o mundo da vida e com os outros homens e mulheres. 
O que realmente se destaca é que, caso a performance obedeça às exigencies pirrônicas, qualquer que seja o resultado será valioso (epistemicamente valioso, moralmente valioso, humanamente valioso).

\section{Uma pessoa entre outras pessoas}

I2. O pirrônico é aquele que, afinal, aprendeu que é uma pessoa entre outras pessoas. E vivendo entre pessoas não há como evitar o infindável conflito de opiniōes e os desacordos intelectuais ${ }^{5}$.

Existem vários cenários de desacordo (FrANCES, 2014, p. 9-IO4). Inclinaçóes ideológicas, pontos de vista, conflitos religiosos, hábitos culturais, jurisdição, gosto, podem gerar infinitas situaçôes de desacordo. É possível, inclusive, que façamos uma distinção entre desacordos genuínos (que envolvem as mesmas informações relevantes, evidências, tempo, credibilidade intelectual, conhecimento prévio e circunstâncias de investigação) e desacordos ilusórios (quando os agentes estão em posiçóes muito desiguais em relação às informaçôes, evidências etc.). Como vimos, o desacordo que interessam ao filósofo são aqueles que, como nos diálogos platônicos que têm Sócrates como protagonista, desenrolam-se me torno de assuntos fundamentais para nossas vidas e de inescapáveis conflitos de opiniôes. Nessas situações, o que é marcante entre aqueles que seguiram o estilo de vida exemplificado pelos céticos antigos é que são pessoas dispostas a assumir uma posição radicalmente diferente de todos os outros filósofos e não-filósofos: elas não apenas reconhecem a existência de desacordos, elas estão dispostas a (elas são treinadas para) aceitar a razoabilidade e racionalidade do desacordo.

I3. Uma das perguntas centrais da filosofia contemporânea sobre o desacordo epistêmico é: o que se deve fazer quando se tem consciência do desacordo, permanecer acreditando na crença de partida, renunciar a essa crença ou suspender o juízo? ${ }^{6}$ Entretanto, eu estou motivado a pensar a partir de duas outras perguntas. A primeira é: independente do que se deve fazer quando se tem consciência do desacordo, o que essa consciência do desacordo (em um cenário cético-dialético) promove epistemicamente na pessoa? A segunda pergunta é: o que faz com que alguém se envolva em diálogos estruturados na forma de desacordos cético-dialético?

\footnotetext{
5 Eu apresentei uma primeira versão do tema que desenvolvo a partir daqui em Silva Filho, 20I8, e Silva Filho \& Rocha, 2018.

6 Um panorama da discussão contemporânea sobre os desacordos se encontra, entre as principais publicaçóes, em Feldman \& Warfield, 20IO, Machuca, 2013, Christensen \& Lackey, 20I3, Frances, 20I4, Matheson, 20I5.
} 
A resposta à primeira pergunta me parece simples: uma vez que os filósofos não podem lograr encontrar a verdade ou elaborar uma teoria que suplante definitivamente as teorias rivais, a sua arte pode ao menos lhes tornar pessoas tolerantes, razoáveis, sensíveis ao que se lhes aparece; ela pode se tornar, sobretudo, uma pessoa que evita e combata o dogmatismo e os vícios morais e intelectuais que tornam a pessoa insensível à razoabilidade da diversidade de opinióes.

Mas isso não é suficiente para responder a segunda pergunta: o que faz com que uma pessoa permaneça no diálogo e aceite as elevadas exigências morais do pirrônico? De certo modo, essa pergunta se conecta com o tema da coerência do ceticismo como uma forma de vida - uma suspeita que o próprio Sexto teve a oportunidade de enfrentar (HP I 2I-24). Eu acho que o modo como os comentadores e historiadores da filosofia abordam esse assunto é excessivamente dramático, como se tratasse de uma conversão a uma espécie de religião: alguém pode viver plenamente como um cético ideal, renunciando a todas as crenças (no caso dos rústicos) ou, ao menos, a todas as crenças dogmáticas (no caso dos urbanos)? Eu entendo as coisas de um modo mais modesto. Primeiramente, para adotar uma fórmula usada por Pierre Hadot (1970), eu penso nas filosofias mais ou menos como formas de exercícios espirituais que estão a serviço daqueles que examinam, investigam e refletem acerca das irregularidades do mundo (entre aquilo que se lhes aparece e aquilo que pensam) e dos desacordos perturbadores. Essas pessoas que leem e conversam com filósofos adquirem diferentes habilidades (análise lógica de argumentos, capacidade de opor argumentos, referências teóricas de autores que já examinaram aquele problema antes etc.) e desenvolvem certas virtudes, como a paciência, a generosidade, a tolerância.

I4. Seria dramático demais esperar que as pessoas se convertam. Mas não seria excessivo esperar que as pessoas estejam cientes da diferença entre, de um lado, um argumento consistente e uma asserção e, do outro, uma aposta, uma crença vaga e sem fundamentos. A filosofia nos dá o poder de avaliar nossas performances intelectuais: ser racional ou não racional é um juízo avaliativo, não é uma descrição, nem é uma necessidade; é uma necessidade apenas nesse cenário: se adotamos uma postura cética, não temos como assentir àquilo que não é evidente; se não fazemos isso — e, de fato, frequentemente não fazemos isso — não nos tornamos menos humanos, apenas nos tornamos mais dogmáticos (paciência!)

Se se adota essa postura que se aprende com os exercícios pirrônicos, a pessoa permanece no diálogo; alias, para as pessoas que adotam essa postura, o diálogo é seu lugar natural. Ela é educada para isso. Uma pessoa entre outras pessoas. 


\section{Ainda é preciso ser neopirrônico}

I5. Estudos dos textos de Sexto e a convivência com filósofos céticos pode nos ajudar ver na filosofia uma maneira de nos educarmos para participar de diálogos na imensidáo dos desacordos entre pessoas sobre aquilo que é humanamente relevante.

As "pessoas de talento" de que fala Sexto (HP I, I2) podem ser mais do que homens e mulheres cultos, como scholars; podem ser pessoas educadas para procurar a verdade $\mathrm{e}$, além disso, para não dar seu assentimento àquilo que não é evidente (HP I, I3 e I93), ela deve saber contrapor, quando for o caso, um argumento a outro de igual valor (HP I, I2), observar não dogmaticamente a vida comum (HP I 23) e dominar certas técnicas que, em disputas dogmáticas, levem à suspensão do juízo (HP I, 3I-I86). São "talentosas" também por outra razão: são capazes de praticar um certo "ceticismo antecedente" e, logo no início da investigação, terem a habilidade de suspender o juízo sobre as próprias crenças fundamentais porque, por exemplo, ouviu ou leu atentamente as liçóes das Hipotiposes ou teve demoradas conversas com filósofos e, de algum modo, passou a ser influenciada por esse aprendizado (Smith, 20I8). Para essa pessoa, a suspensão já se encontra no início da investigaçáo, uma vez que, caso contrário, dificilmente ela conseguiria aceitar a plausibilidade do desacordo racional, o conflito legítimo de opinióes e a ocorrência de argumentos de igual valor epistêmico.

O resultado da investigação filosófica conduzida pelo pirrônico pode não ser a verdade ou uma nova teoria, mas algo táo valioso ou talvez ainda mais valioso: a autonomia e a liberdade intelectual, uma atitude mais exigente, desconfiada de certas afirmaçóes e, curiosamente, mais capaz de compreender posiçóes diferentes da sua. Ainda é preciso ser neopirrônico porque a atitude intelectual pirrônica de cultivar certas capacidades e habilidades são virtuosas, evitam a precipitaçáo, a arrogância etc. que produzem uma visão dogmática do mundo.

\section{Referências}

Bailey, A. (2002). Sextus Empiricus and Pyrrhonean Scepticism. Oxford: Clarendon Press.

Battaly, H. (20I4). "Varieties of epistemic vice", in: Matheson, J. \& Vitz, R. (eds.) The Ethics of Belief. Oxford : Oxford University Press, p. 5I-76.

Battaly, H. (2018). "Closed-mindedness and dogmatism", in: Episteme, p. I-22, DOI:Io.IOI7/epi.2018.22.

Cassam, Q. (2016). "Vice epistemology", in: The Monist, Vol. 99, p. I59-I80, DOI: IO.IO93/monist/onvo34.

Cassam, Q. (2019). Vices of the Mind: From the Intellectual to the Political. Oxford: Oxford University Press.

Chalmers, D. (201I). "Verbal disputes", in: Philosophical Review, Vol. I20, No. 4, p. 515-566. 
Christensen, D. \& Lackey, J. (2013). The Epistemology of disagreement. New York: OUP.

Feldman, R. \& Warfield, T (2010). Disagreement. New York: Oxford University Press.

Frances, B. (20I4). Disagreement. Cambridge: Polity.

Hume, D. (1748). Investigaçôes sobre o Entendimento Humano e sobre os Princípios da Moral. Tradução de José Oscar de A. Marques. São Paulo: Editora UNESP, 2003.

Kidd, I. (2017). "Capital Epistemic Vices”, in: Social Epistemology Review and Reply Collective, 6, p. II-I7.

Machuca, D. (2018). "Pyrrhonian argumentation: therapy, dialetic, and inquiry", in: Apeiron, p. I-23, doi.org/IO.I515/apeiron-2018-00I7.

Machuca, D. (ed.) (2013). Disagreement and Skepticism. NY, London: Routledge.

Matheson, J. (20I5b). The Epistemic Significance of Disagreement. London: Palgrave Macmillan.

Porchat, O. (1991). "Sobre o que aparece", in: Revista Latinoamericana de Filosofía, vol. XVII, n. 2, p. 195-229.

Porchat, O. (200I). "Ainda é preciso ser cético", in: Discurso, n. 32, p. 9-30.

Porchat, O. (2006). Rumo ao Ceticismo. São Paulo: Editora UNESP.

Silva Filho, W. J. (2018). "O que aprendi (lendo e conversando) com filósofos céticos", in: Skepsis, Vol. IX, n. I7, p. I46-156.

Silva Filho, W. \& Rocha, F. (2018). "Disagreement and Reflection", in: Ruivo, L. (ed.). Proceedings of the Brazilian Research Group on Epistemology: 2018. Porto Alegre, RS: Editora Fi, 20I8, p. I07-I2I.

Smith, P. J. (2017). Uma Visão Cética do Mundo: Porchat e a Filosofia. São Paulo: Editora UNESP.

Smith, P. J. (2018). "Neopirronismo e desacordo", in: Sképsis, Vol. IX, n. I7, p. II4-I34.

Tanesini, A. (2016). "'Calm Down, Dear': Intellectual Arrogance, Silencing, and Ignorance", in: Aristotelian Society: Supplementary Volume 90, no. I, p. 71-92.

Zagzebski, L. T. (1996). Virtue of the Mind: An Inquiry into the Nature of Virtue and the Ethical Foundations of Knowledge. Cambridge: Cambridge University Press. 